\title{
Moist Potential Vorticity Vector for Diagnosis of Heavy Rainfall Events in Tanzania
}

\author{
Philbert Modest Luhunga',2, George Djolov ${ }^{1}$, Edmund Mutayoba ${ }^{3}$ \\ ${ }^{1}$ Department of Geography, Geo-Informatics and Meteorology, University of Pretoria, Pretoria, South Africa \\ ${ }^{2}$ Research Section, Tanzania Meteorological Agency, Dar es Salaam, Tanzania \\ ${ }^{3}$ Department of Built Environmental Engineering, Mbeya University of Science and Technology, Mbeya, Tanzania \\ Email:philuhunga@yahoo.com,george.djolov@up.ac.za,edmuta27@gmail.com
}

How to cite this paper: Luhunga, P.M., Djolov, G. and Mutayoba, E. (2016) Moist Potential Vorticity Vector for Diagnosis of Heavy Rainfall Events in Tanzania. Journa of Geoscience and Environment Protection, 4, 128-145.

http://dx.doi.org/10.4236/gep.2016.49010

Received: May 31, 2016

Accepted: September 26, 2016

Published: September 29, 2016

Copyright $\odot 2016$ by authors and Scientific Research Publishing Inc. This work is licensed under the Creative Commons Attribution International License (CC BY 4.0).

http://creativecommons.org/licenses/by/4.0/ (c) (i) Open Access

\begin{abstract}
In this paper, we modify the convective vorticity vector ( $C V V)$ defined as a cross product of absolute vorticity and gradient of equivalent potential temperature to moist potential vorticity vector (MPVV) defined as a cross product of absolute vorticity $\left(\zeta_{a}\right)$ and the gradient of the moist-air entropy potential temperature $\left(\theta_{s}\right)$. The patterns of (MPVV) are compared with the patterns of heavy rainfall events that occurred over different regions in Tanzania on $20^{\text {th }}$ to $22^{\text {nd }}$ December, 2011 and on $5^{\text {th }}$ to $8^{\text {th }}$ May, 2015. Moreover, the article aimed at assessing the relative contributions of the magnitude, horizontal and vertical components of (MPVV) detecting on the observed patterns of rainfall events. Dynamic and thermodynamic variables: wind speed, temperature, atmospheric pressure and relative humidity from numerical output generated by the Weather Research and Forecasting (WRF) model running at Tanzania Meteorological Agency (TMA) were used to compute MPVV. It is found that $M P V V$ provide accurate tracking of locations received heavy rainfall, suggesting its potential use as a dynamic tracer for heavy rainfall events in Tanzania. Finally it is found that the first and second components of MPVV contribute almost equally in tracing locations received heavy rainfall events. The magnitude of MPVV described the locations received heavy rainfall events better than the components.
\end{abstract}

\section{Keywords}

Moist Potential Vorticity Vector, Moist-Air Entropic Potential Temperature, Heavy Rainfall Events

\section{Introduction}

In recent years, extreme weather events such as heavy rainfall are common and have 
contributed to loss of lives, damage of properties, destruction of environment and other social economic livelihood of people in many countries [1] [2]. Tanzania has witnessed many heavy rainfall events in recent years. Table 1 depicts some of the more recent heavy rainfall events which have occurred over different regions in Tanzania. Forecasting of these events is of considerable benefit to different sectors (agriculture, hydropower, health, water resources) and community at large. However, it is difficult to forecast these events accurately and reliably [3] [4]. In Tanzania, the difficulty to forecast heavy rainfall is associated with the country's complex topographical landscapes, numerous large inland water bodies, variation in vegetation types and land-ocean contrast [5].

Several studies [5]-[7] have analysed the drivers of heavy rainfall events over East African region in general and Tanzania in particular. [6] analyzed the link between El Nino events in the equatorial Indian Ocean and the catastrophic rainfall of 1961-1962 in East Africa. They found that, heavy rainfall over East African region is associated with large Sea Surface Temperatures (SSTs) and wind anomalies over equatorial Indian Ocean. [5] analysed the atmospheric circulation patterns over the Indian Ocean that was linked to heavy rainfall event that occurred over northern Tanzania during the short rain of October-November-December (OND) season in 2006. They found that heavy rainfall was associated with strong warming over the Indian Ocean, coupled with convective zones over the western Indian Ocean and East African region.

The above mentioned studies have analysed the impacts of large scale atmospheric circulation, atmosphere-ocean interactions and SSTs on heavy rainfall events. However, relatively less attention has been directed towards analysing the impact of local scale induced circulations from orography, land ocean contrast and difference in vegetation

Table 1. Regions received heavy rainfall from 2011 to 2015 in Tanzania.

\begin{tabular}{ccccccc}
\hline No. & Region & Lat (S) & Lon $(\mathrm{E})$ & Alt $(\mathrm{m})$ & Rainfall (mm/day) & Date of heavy rainfall \\
\hline 1 & Tukuyu, Mbeya & 08.56 & 33.28 & 1758 & 232 & $09 / 11 / 2011$ \\
2 & Dar es Salaam & 06.53 & 39.12 & 53 & 156.4 & $20 / 12 / 2011$ \\
3 & Iringa & 07.40 & 35.45 & 1428 & 131 & $21 / 12 / 2011$ \\
4 & Kizimbani, Zanzibar & 06.13 & 39.13 & 18 & 130.2 & $19 / 04 / 2011$ \\
5 & Mtwara & 10.21 & 40.11 & 113 & 100 & $18 / 02 / 2011$ \\
6 & Tanga & 05.05 & 39.04 & 49 & 100.6 & $11 / 10 / 2011$ \\
7 & Zanzibar & 06.13 & 39.13 & 18 & 133.8 & $19 / 04 / 2011$ \\
8 & Dar es Salaam & 06.53 & 39.12 & 53 & 133.8 & $11 / 04 / 2012$ \\
9 & Mwanza & 02.28 & 32.55 & 1140 & 142 & $31 / 10 / 2012$ \\
10 & Zanzibar & 06.13 & 39.13 & 18 & 116.2 & $26 / 11 / 2012$ \\
11 & Dar es Salaam & 06.53 & 39.12 & 53 & 138.1 & $11 / 04 / 2014$ \\
12 & Dar es Salaam & 06.53 & 39.12 & 53 & 111.4 & $6 / 5 / 2015$ \\
13 & Kibaha & 06.50 & 38.38 & 167 & 88.3 & $6 / 5 / 2015$ \\
14 & Zanzibar & 06.13 & 39.13 & 18 & 45.5 & $6 / 5 / 2015$ \\
\hline
\end{tabular}


type on formation of heavy rainfall events. Furthermore the combined impact of local and large scale circulations to the atmospheric environment at which was the main cause of heavy rainfall events have not been analysed. In this study, we modify the convective vorticity vector ( $C V \boldsymbol{V})$ which is defined as a cross product of absolute vorticity and gradient of equivalent potential temperature to moist potential vorticity vector MPVV by replacing the equivalent potential temperature with the moist-air entropy potential temperature $\left(\theta_{s}\right)$. The usefulness of $\mathbf{M P V V}$ in diagnosis of heavy rainfall events is analysed. The ultimate goal is to highlight the possibilities of using MPVV to help prediction of heavy rainfall events over different regions in Tanzania.

\section{Motivation of the Use of New Moist Potential Vorticity Vector to Describe Rainfall Events}

Heavy rainfall events, among other factors are triggered by transport and convection of large volume of water vapour. Physical variable such as moist potential vorticity (MPV), that describe both dynamics and thermodynamics aspect of water vapour can be used to diagnose and potentially predict the occurrence and distribution of heavy rainfall [8]. Indeed, MPV combines the two general characteristics responsible for the rainfall formation: the dynamics via the vorticity component and the thermodynamics via the gradient of the moist-air temperature. [9] used MPV as a fundamental dynamical variable to examine a four dimensional dataset obtained from an 18-hr high resolution 25 $\mathrm{km}$ simulation of a squall line that occurred during 1200UCT 10 June to 0600UCT 11 June 1985. They found that the stratiform region is characterised by negative MPV and suggest that trailing stratiform precipitation could be viewed as an end of slantwise convection with pronounced moist symmetric instability (MSI). [8] used MPV as a diagnostic variable of heavy rainfall event that occurred in MEIYU and found that MPV is an important physical variable to reveal heavy rainfall structure and dynamic mechanisms. They also found that negative MPV correspond to the MEIYU front-wind shear line system and the negative center corresponds to the heavy rain center.

However, the scalar MPV which is derived from the dot product of absolute vorticity and gradient of moist-air temperature may not fully explain the complex atmospheric circulations patterns over the tropics. The Coriolis parameter over the tropics is very small and is zero over the equator. Furthermore the vertical gradient of temperature over the tropics is small due to strong mixing processes. Thus the scalar MPV may not represents some dynamical patterns over the tropics, particularly close to equatorial region. For instance, [10] demonstrated that the vertical component of planetary vorticity in MPV computation is zero and cannot explain two dimension (2-D) equatorial atmospheric flows. [11] argued that over the tropics, the moist potential vorticity computed from the dot product is mainly in the horizontal direction since the absolute vorticity and the gradient of temperature are small and cannot represent the atmospheric motions reasonably. [10] proposed the use of convective vorticity vector ( $C V \boldsymbol{V})$ to study deep convection particularly over tropical regions. However, $\mathbf{C V} \boldsymbol{V}$ is computed using the gradient of equivalent potential temperature $\theta_{e}$. It is conservative only in moist 
adiabatic and frictionless processes and its generalization to be used in dry atmosphere lead to annihilation of solenoidal term in its tendency equation [12]. Since the atmosphere is never completely dry or saturated, but non-uniformly saturated. Thus $\mathbf{C V V}$ cannot be used to study non-uniform saturated atmospheric flow and fulfil the demand to verify, at the same time, a moist and dry air conservative property and an invertibility principle. In this study we modify $\boldsymbol{C V} \boldsymbol{V}$ to moist potential vorticity vector (MPVV) by replacing the equivalent potential temperature with moist-air entropy potential temperature $\left(\theta_{s}\right)$. This temperature is valid for a general mixing of dry air, water vapour and all possible condensed water species. MPVV is analysed on its ability to diagnose heavy rainfall events over different regions in Tanzania.

\section{Data and Methodology}

\subsection{Model Description Experimental Design and Data from the Model}

The Weather Research and Forecasting (WRF) model version 3.3.1, jointly developed by the National Oceanic and Atmospheric Administration (NOAA) and National Centre for Atmospheric Research (NCAR) is used in this study. This model is a non-hydrostatic mesoscale NWP model, fully compressible and has terrain following sigma coordinates [13] [14]. The WRF is chosen in this study because it has been used by different researchers at government institution and universities and is currently running at Tanzania Meteorological Agency (TMA) Numerical Weather Prediction (NWP) modelling section. It features multiple dynamical cores, a 3-dimensional variation and 4-dimensional (3DVAR and 4DVAR) data assimilation system, and has software architecture that allow for computational parallelism. WRF is suitable for a broad spectrum of applications across scales ranging from meters to thousands of kilometres.

In this study the domain of $\mathrm{WRF}$ is set-up over East Africa region $\left(8^{\circ} \mathrm{N}\right.$ to $18^{\circ} \mathrm{S} ; 25^{\circ} \mathrm{E}$ to $52^{\circ} \mathrm{E}$ ) (Figure 1), on a horizontal resolution of $15 \mathrm{~km}$, and the model has 28 vertical levels. The model was set to simulate heavy rainfall events that occurred over different regions in Tanzania from $20^{\text {th }}$ to $22^{\text {nd }}$ December 2011 and $5^{\text {th }}$ to $8^{\text {th }}$ May 2015. The boundary condition from the National Centre for Environmental Prediction (NCEP) global forecast system (GFS) dataset with a $0.5^{\circ} \times 0.5^{\circ}$ spatial resolution were used to force the WRF. The input data has a time interval of three hours, while the output data are served at hourly interval. The simulations were initiated at 00h UTC and run for 48 hours ahead. Simulated meteorological variables: wind speed (zonal, meridional and vertical components), pressure, temperature and relative humidity at different pressure levels are used to compute $\mathbf{M P V V}$.

\subsection{Rainfall Data}

Rainfall as cumulated total for every 3 hours was accessed from the Tropical Rainfall Measuring Mission (TRMM). This is an international project led by the National Aeronautics and Space Administration (NASA) and Japan Aerospace Exploration Agency (JAXA). The project provides improved estimate of rainfall over tropical regions using remote sensing technique through satellite observations. The TRMM rainfall 


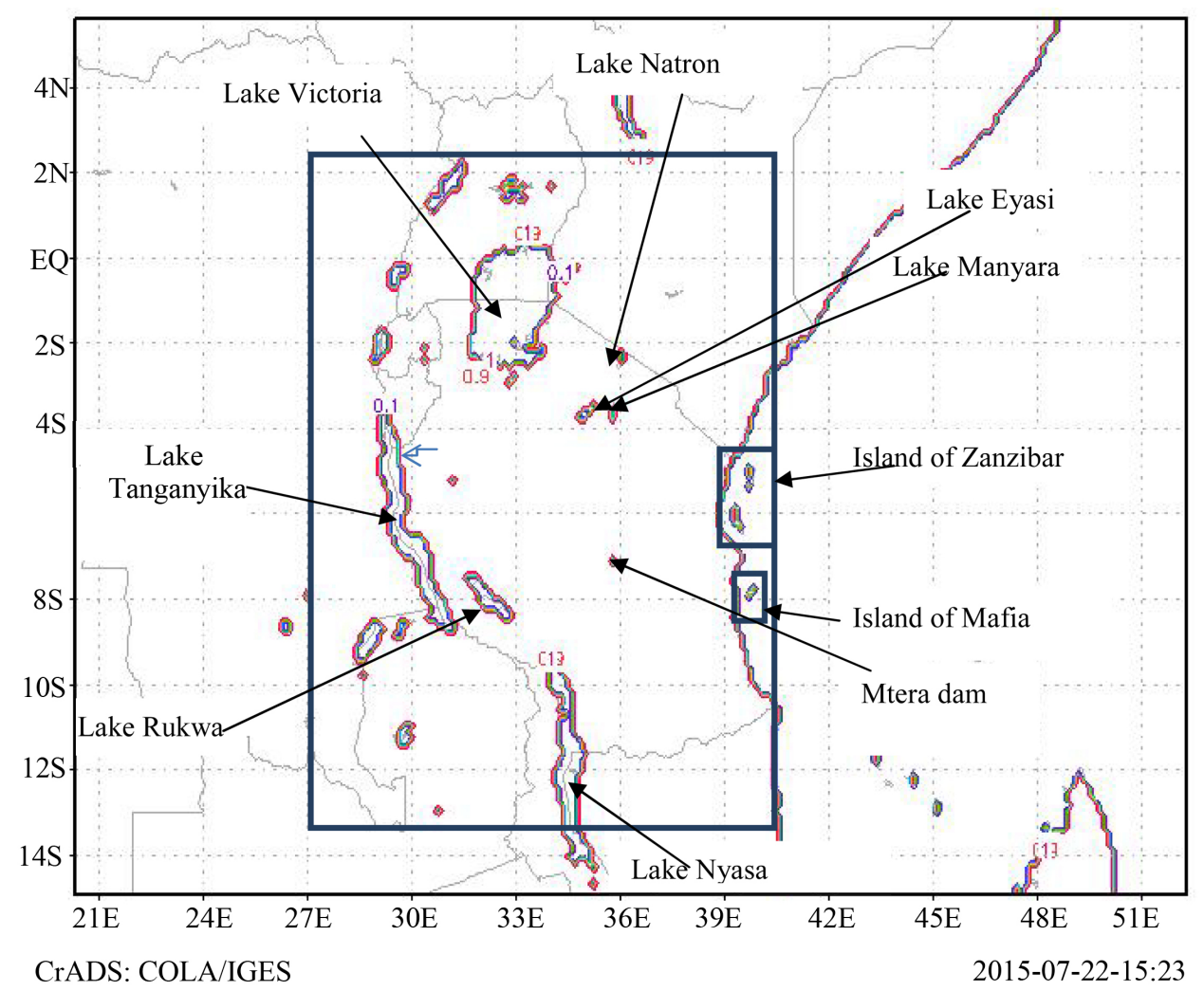

Figure 1. The topographical map in the domain where WRF is set indicating surface land cover that can be resolved by the model in the study region.

estimates used here are from TRMM 3B42V7, available at spatial resolution of $0.25^{\circ}$ by $0.25^{\circ}$ which is approximately $27.8 \mathrm{~km}$ by $27.8 \mathrm{~km}$. These data were accessed from the website:

http://giovanni.sci.gsfc.nasa.gov/giovanni/\#service $=$ TmAvMp\&starttime=\&endti and was used to map the spatial distribution of rainfall ( $\mathrm{mm} /$ day) during $20^{\text {th }}$ to $22^{\text {nd }}$ December 2011 and $5^{\text {th }}$ to $8^{\text {th }}$ May 2015. These maps are compared with the spatial patterns of MPVV .

\subsection{Observed Rainfall Data}

Daily accumulated rainfall $\left(\mathrm{mm} /\right.$ day) during $20^{\text {th }}$ to $22^{\text {nd }}$ December 2011 and $5^{\text {th }}$ to $8^{\text {th }}$ May 2015 were acquired from the Tanzania Meteorological Agency (TMA). In order to compare the spatial patterns of MPVV with rainfall, the Inverse Distance Weighting (IDW) interpolation technique was used to interpolate the patterns of observed rainfall using data from 22 weather stations. For detailed description about the IDW interpolation technique a reader may consult [15]. The spatial rainfall maps generated using IDW interpolation techniques are compared with spatial patterns of $M P V V$.

\subsection{Descriptions of Rainfall Events}

On $20^{\text {st }}$ to $22^{\text {nd }}$ December 2011, there was very heavy rainfall over the city of Dar es Sa- 
laam which triggered a worst flooding event where forty three people were reported dead and many were missing. The major transportation networks of the city were destroyed by the flood. Some bridges were completely swept out and others were covered with water. The heavy rainfall event were caused by warming over the eastern, North and northwestern Australia and the prevailed surface Westerly wind, that pushed warm surface water towards western Indian Ocean. This warm surface water spread around western equatorial Indian Ocean coupled with significant warming developed over western Indian Ocean (coast of Dar es Salaam) on 20-22 December enhanced more convection along the coastal regions. Moreover, low level convergence dominated over most regions that enhanced heavy rainfall over much parts of the country. Figure 2 indicates the cloud band over the coastal region detected from satellite image on 21-122011, at 0900UCT.

On $6^{\text {th }}$ May 2015, the city of Dar es Salaam received heavy rainfall of $111.4 \mathrm{~mm}$ in 24-hours. Kibaha region received $88.3 \mathrm{~mm}$ in 24-hours, while Zanzibar reported 45.5 $\mathrm{mm}$ in 24-hours. On the $7^{\text {th }}$ May 2015, rainfall of $60.2 \mathrm{~mm}, 52.5 \mathrm{~mm}, 49.7 \mathrm{~mm}, 41.4$ $\mathrm{mm}$ and $37.4 \mathrm{~mm}$ were reported at Mahenge, Dar es Salaam, Kibaha, Zanzibar and

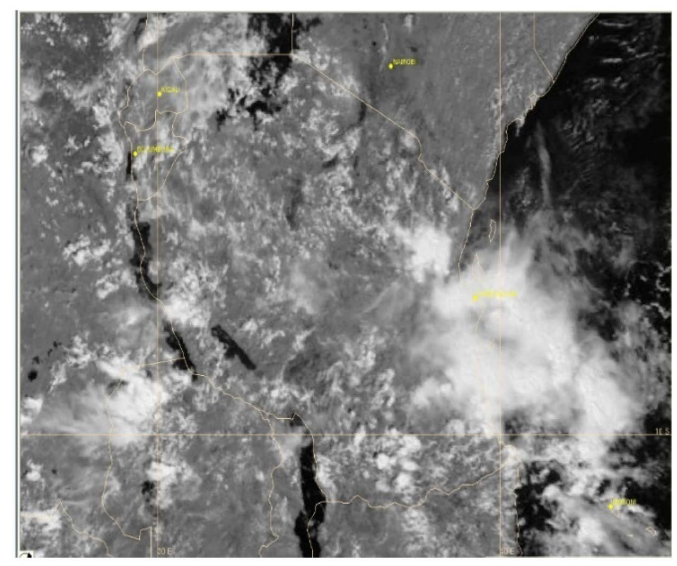

(a)

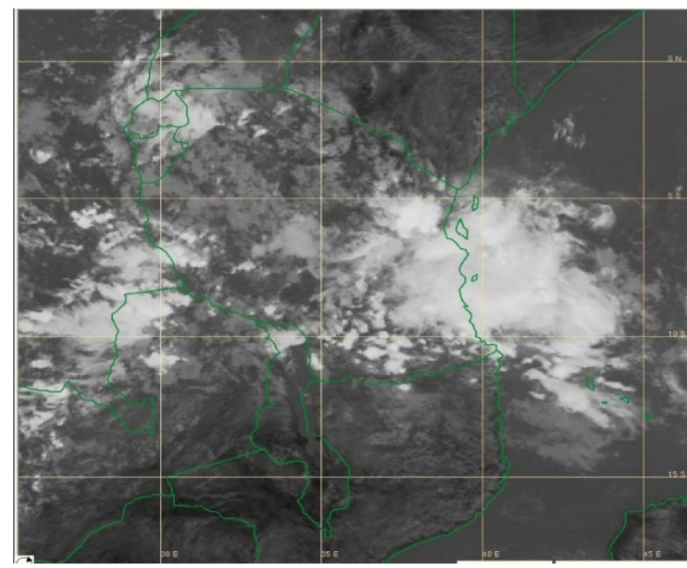

(b)

Figure 2. Satellite image (a) visible band; (b) infrared band on 21-12-2011, at 0900UCT. 
Mtwara regions respectively. These rainfalls were influenced by the enhancement of the inter-tropical convergence zone (ITCZ) over Tanzania, and significant moisture flux over the coastal belt coupled with low level convergence that triggered deep convection over most regions.

\subsection{Modification of $C V V$ to $M P V V$}

We start by defining the moist-air entropy potential temperature. The moist-air entropy potential temperature $\theta_{s}$ is defined in [16] as

$$
\begin{gathered}
\theta_{s} \equiv\left(\theta_{s}\right)_{1}\left(\frac{T}{T_{r}}\right)^{\lambda q_{t}}\left(\frac{p}{p_{r}}\right)^{-k \delta q_{t}}\left(\frac{r_{r}}{r_{v}}\right)^{q_{t}} \frac{\left(1+\eta r_{v}\right)^{k\left(1+\delta q_{t}\right)}}{\left(1+\eta r_{r}\right)^{k \delta q_{t}}}, \\
\left(\theta_{s}\right)_{1}=\theta \exp \left(\Lambda_{r} q_{t}\right) \exp \left(-\frac{L_{v} q_{l}+L_{s} q_{i}}{c_{p d} T}\right),
\end{gathered}
$$

where $\Lambda_{r}=\frac{\left(s_{v}^{0}-s_{d}^{0}\right)}{c_{p d}} \approx 5.87$ is a key quantity. It is mentioned in [16] that $\Lambda_{r}$ depends on the standard entropies of water vapour and dry air $\left(s_{v}^{0}\right)$ and $\left(s_{d}^{0}\right)$. It is also mentioned that $\left(\theta_{s}\right)_{1}$ is a good approximation of $\theta_{s}$. For detailed derivation of $\theta_{s}$ please refer to [16]-[18].

Another parameter to use in computation of $\boldsymbol{M P V V}$ is density $\rho$ which is defined from the equation of state as

$$
\rho=\frac{p}{\theta(\rho, p) R_{d}}\left(\frac{p_{0}}{p}\right)^{k}
$$

where $p$ is atmospheric pressure (in $\mathrm{Pa}$ ) at different level, $p_{0}$ is atmospheric pressure at reference level, $\theta(\rho, p)$ is potential temperature, $R_{d}$ is specific gas constant for dry air and $k=\frac{R_{d}}{C_{p}}, C_{p}$ is specific heat capacity at constant pressure. The last parameter used for computing $\mathbf{M P V V}$ is the absolute vorticity which is defined as

$$
\boldsymbol{\zeta}_{a}=-\frac{\partial v}{\partial z} \boldsymbol{i}+\frac{\partial u}{\partial z} \boldsymbol{j}+(\boldsymbol{\zeta}+f) \boldsymbol{k}
$$

where $\boldsymbol{\zeta}$ is the relative vorticity defined as $\boldsymbol{\zeta}=\left(\frac{\partial v}{\partial x}-\frac{\partial u}{\partial y}\right) \boldsymbol{k}+\frac{u}{a} \tan (\varphi)$, where $a$ is the radius of the earth and $\varphi$ is the latitude, $f$ is the coriolis parameter defined as $f=2 \Omega \sin (\varphi)$.

MPVV is defined as

$$
\boldsymbol{M P V V}\left(\theta_{s}\right)=\frac{1}{\rho}\left(\begin{array}{c}
-\frac{\partial v}{\partial z} \\
\frac{\partial u}{\partial z} \\
(\zeta+f)
\end{array}\right) \times\left(\begin{array}{c}
\frac{\partial \theta_{s}}{\partial x} \\
\frac{\partial \theta_{s}}{\partial y} \\
\frac{\partial \theta_{s}}{\partial z}
\end{array}\right)=\frac{1}{\rho}\left(\begin{array}{c}
\frac{\partial u}{\partial z} \frac{\partial \theta_{s}}{\partial z}-(\zeta+f) \frac{\partial \theta_{s}}{\partial y} \\
\frac{\partial v}{\partial z} \frac{\partial \theta_{s}}{\partial z}+(\zeta+f) \frac{\partial \theta_{s}}{\partial x} \\
-\frac{\partial v}{\partial z} \frac{\partial \theta_{s}}{\partial y}-\frac{\partial u}{\partial z} \frac{\partial \theta_{s}}{\partial x}
\end{array}\right)=\left(\begin{array}{c}
\boldsymbol{M P V V} \boldsymbol{V}_{x} \\
\boldsymbol{M P V V} \boldsymbol{V}_{y} \\
\boldsymbol{M P V V} \boldsymbol{V}_{z}
\end{array}\right)
$$


Considering the hydrostatic equilibrium $\partial / \partial z=-\rho g \partial / \partial p$, Equation (5) can be rewritten as

First component $\boldsymbol{M P V V}_{x}=\rho g^{2} \frac{\partial u}{\partial p} \frac{\partial \theta_{s}}{\partial p}-\frac{(\zeta+f)}{\rho} \frac{\partial \theta_{s}}{\partial y}$,

Second component $\boldsymbol{M P V V}_{y}=\rho g^{2} \frac{\partial v}{\partial p} \frac{\partial \theta_{s}}{\partial p}+\frac{(\boldsymbol{\zeta}+f)}{\rho} \frac{\partial \theta_{s}}{\partial x}$,

The third component $\boldsymbol{M P V V}_{z}=g\left(\frac{\partial v}{\partial p} \frac{\partial \theta_{s}}{\partial y}+\frac{\partial u}{\partial p} \frac{\partial \theta_{s}}{\partial x}\right)$

The magnitude of $\boldsymbol{M P V V}$ is written as

$$
|\boldsymbol{M P V V}|=\sqrt{\left(\boldsymbol{M P V V}_{x}\right)^{2}+\left(\boldsymbol{M P V V}_{y}\right)^{2}+\left(\boldsymbol{M P V V}_{z}\right)^{2}} .
$$

\section{Results and Discussion}

In this study we analyse whether $\boldsymbol{M P V} \boldsymbol{V}$ can serve as diagnostic variable of heavy rainfall events over different regions of Tanzania. This is achieved by comparing the spatial patterns of $\mathbf{M P V V}$ and rainfall. Starting with the first case, Figure 3 shows the distribution of rainfall estimates derived from satellite, where subplot 3(a) and 3(b) respectively represent accumulated rainfall estimates on $20^{\text {th }}$ and $21^{\text {st }}$ of December, 2011. While subplot $3(\mathrm{c})$ is 48 -hour accumulated rainfall estimates from $20^{\text {th }}$ to $21^{\text {st }}$ December, 2011. It is seen that the distribution of rainfall almost covered the whole domain of Tanzania. However, there are differences in rainfall intensity across the regions. The coastal regions and southwestern highlands received larger amount of rainfall compared to Northern regions and northeastern highlands. The maximum 24-hours accumulated rainfall is seen over Dar es Salaam (Figure 3(a) and Figure 3(b)). These rainfall estimates from satellite collocate with observed rainfall in Figure 4, where maximum rainfall of about $156 \mathrm{~mm}$ was measured over Dar es Salaam weather station on $20^{\text {th }}$ December, 2011. Further, Figure 4 also shows that most regions received rainfall above $22 \mathrm{~mm}$ on $20^{\text {th }}$ December, 2011.

The distribution of the MPVV share similar patterns to that of rainfall areas,

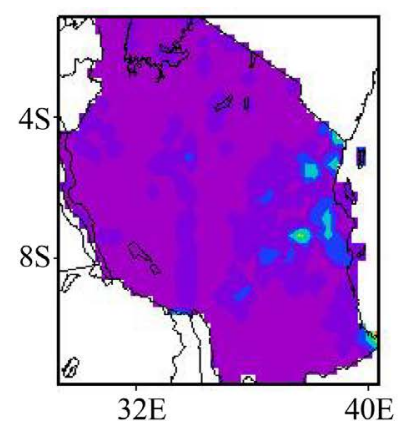

(a)

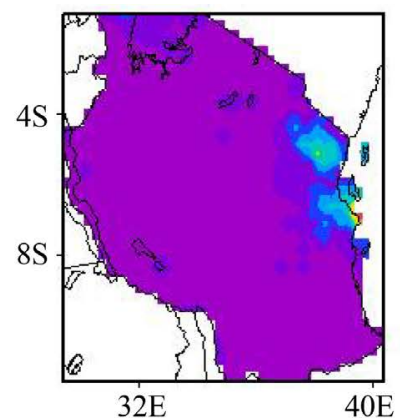

(b)

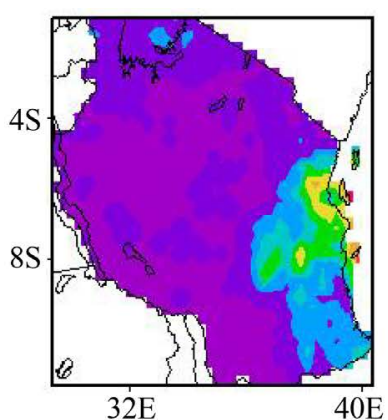

(c)

$$
\begin{array}{llllllll}
0 & 20 & 40 & 60 & 80 & 100 & 120 & 140
\end{array}
$$

Figure 3. Rainfall in mm/day (a) 20/12/2011; (b) 21/12/2011; (c) 20-21/12/2011. 


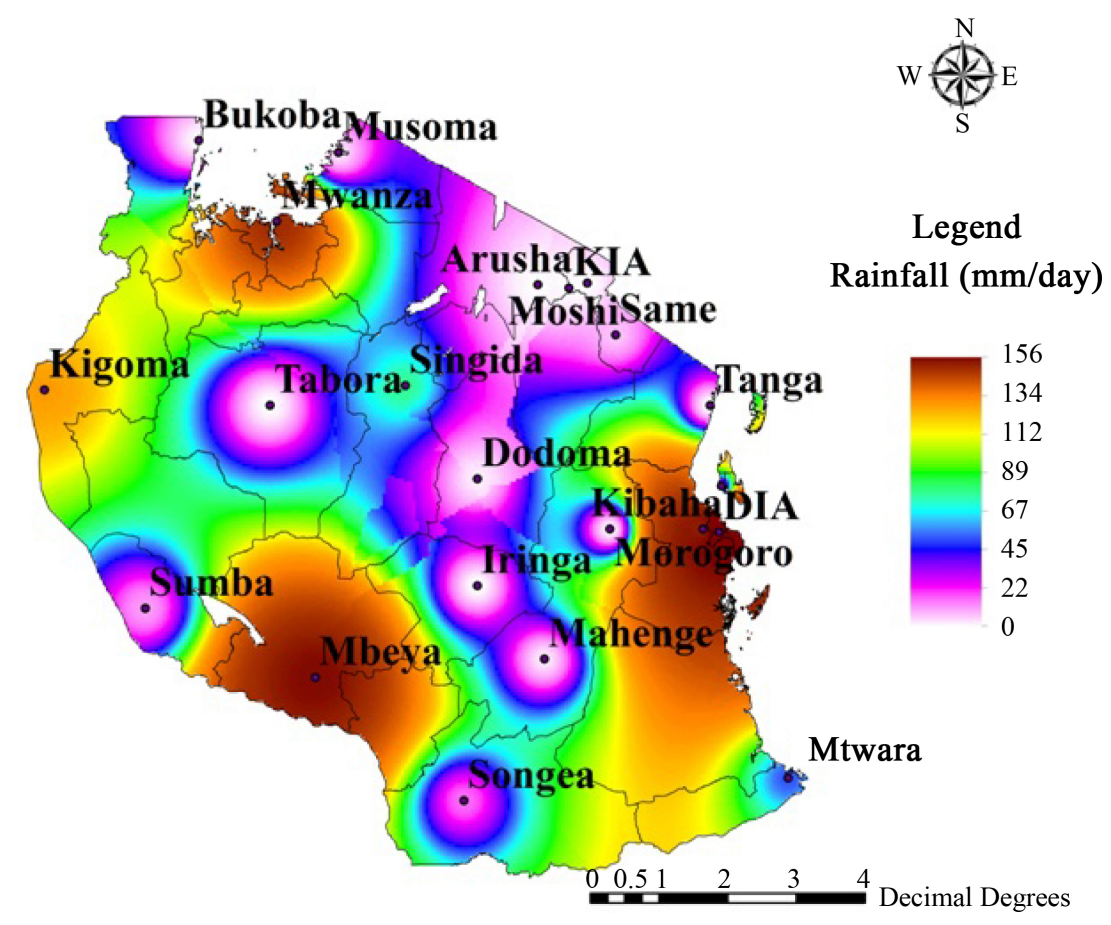

Figure 4. Distribution of observed rainfall over different regions in Tanzania on 20-12-2011.

Figure 5 shows the distribution of the first component of $M P V V$, where subplot 5(a) and 5(b) presents the first component of $M P V V$ at $700 \mathrm{hPa}$ on $20^{\text {th }}$ and $21^{\text {st }}$ December 2011 respectively, while subplot 5(c) is the 48-hour average of $\mathbf{M P V V}$ at $700 \mathrm{hPa}$. The reason why we calculate $\mathbf{M P V V}$ at $700 \mathrm{hPa}$ level and compare with the rainfall areas is due to the fact that, this level is commonly used for diagnosis of rainfall triggering systems over the tropics, particularly in Tanzania. Thus the behaviour of MPVV computed at this level is expected to better represent the pattern of rainfall over different regions compared to MPVV at other levels. The positive values of MPVV are seen distributed almost over the whole domain of Tanzania (Figure 5(a)). This collocates with the distribution of rainfall in Figure 3(a). Positive values of MPVV extended from Congo to western part of Tanzania, where they extended again to northern and southern regions. This distribution may have contributed to the observed high amount of rainfall over the southwestern highlands, where high ground topography may be enhancing convection processes and over southern part of Lake Victoria, where lake-land contrast may be triggering convection activity. However, a negative band of MPVV is seen along the coast (Figure 5(a)). This band is surrounded by positive values of $\boldsymbol{M P V V}$, where maximum values are seen over the Indian Ocean. Figure 5(b) shows the band of negative $M P V V$ extends from the coast to inland, this indicates convective processes over the coast regions reduced on 21 of December 2011.

Figure 6 shows the distribution of the second component of $M P V V$, where subplot 6(a) and 6(b) present the patterns of $M P V V$ on $20^{\text {th }}$ and $21^{\text {st }}$, December 2011 respec- 


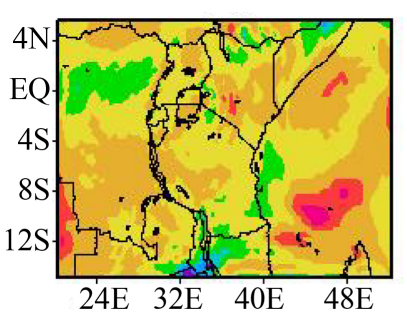

(a)

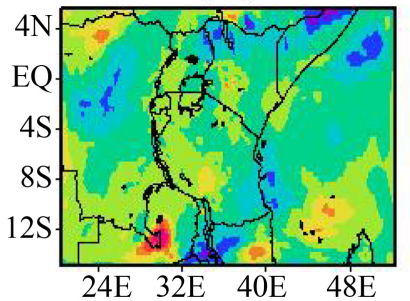

(b)

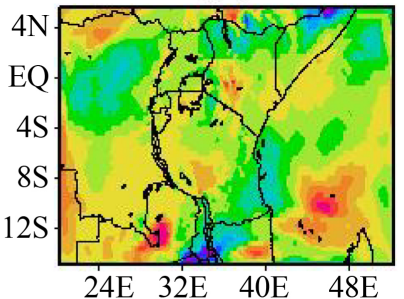

(c)

$$
\begin{array}{llllllllllll}
-7 & -6 & -5 & -4 & -3 & -2 & -1 & 0 & 1 & 2 & 3 & 4
\end{array}
$$

Figure 5. Spatial distribution of the first component of the moist potential vorticity vector (in PV-units) on (a) 20/12/2011; (b) 21/12/2011; (c) 20-21/12/2011.

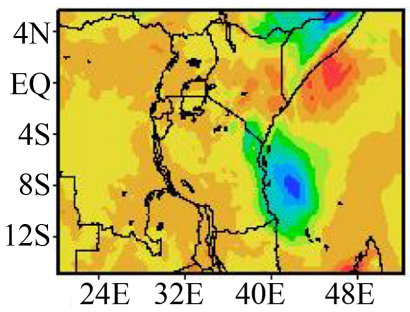

(a)

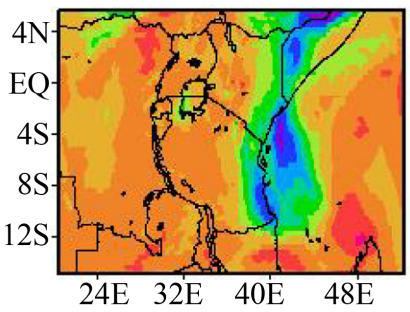

(b)

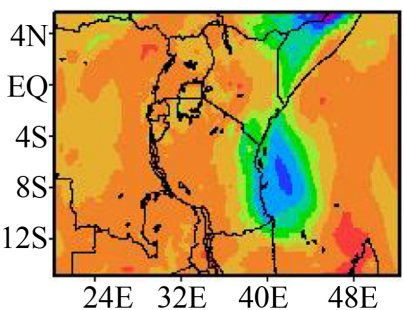

(c)

$\begin{array}{llllllllll}-14 & -12 & -10 & -8 & -6 & -4 & -2 & 0 & 2 & 4\end{array}$

Figure 6. Similar to Figure 5 but for the second component of the moist potential vorticity vector (in PV-units) on (a) 20/12/2011; (b) 21/12/2011; (c) 20-21/12/2011.

tively. Subplot 6(c) is the average of the second component of MPVV from $20^{\text {th }}$ to $21^{\text {st }}$ December 2011. The distributions of the second component of MPVV collocate with the distribution of rainfall locations. Positive values of MPVV are distributed almost over the whole of Tanzania. Similar to what was observed with the first component, the coastal region is dominated with negative values of $M P V V$ which are surrounded with positive values of MPVV . From Figure 6(a), maximum positive values of $M P V V$ are seen over southwestern highland and southern part of the lake Victoria region and parts of central regions this correspond to high rainfall over those areas.

The distribution of the third component of MPVV is shown in Figure 7. From this figure it can be seen that subplot 7(a) and subplot 7(b) which represents the patterns of the third component of $\boldsymbol{M P V V}$ on $20^{\text {th }}$ and $21^{\text {st }}$ December 2011 respectively are dominated with positive values. The 48-hour average of the third component of MPVV shows that the country was dominated with small positive values MPVV (Figure 7(c)).

The magnitude of the MPVV shown in Figure 8 indicates that the band of maximum values of $\boldsymbol{M P V V}$ is located over the coastal regions. This band bear different shapes, on $20^{\text {th }}$ December, it is oriented in south-eastern direction touching the coast, with maximum values of $\mathbf{M P V V}$ located close to Dar es Salaam. This collocated with the observed heavy rainfall over that region that triggered catastrophic flooding event. On $21^{\text {st }}$ December 2011, the band of maximum magnitude of $\boldsymbol{M P V V}$ is oriented 


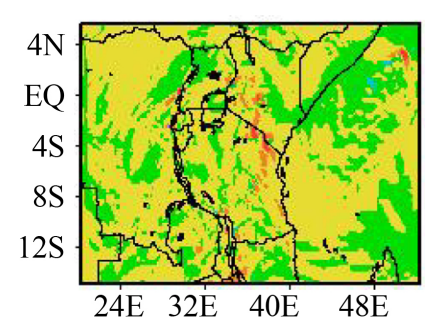

(a)

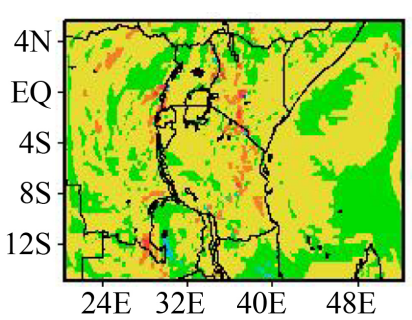

(b)

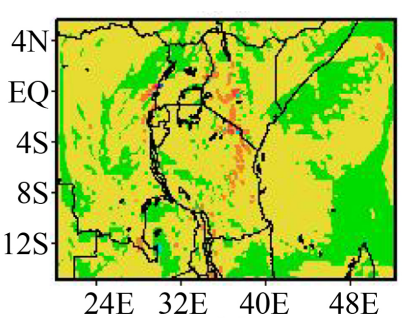

(c)

$$
\begin{array}{llllllll}
-0.3 & -0.2 & -0.1 & 0 & 0.1 & 0.2 & 0.4 & 0.6
\end{array}
$$

Figure 7. Similar like Figure 6 but for third component of the moist potential vorticity vector (in PV-units) on (a) 20/12/2011; (b) 21/12/2011; (c) 20-21/12/2011.

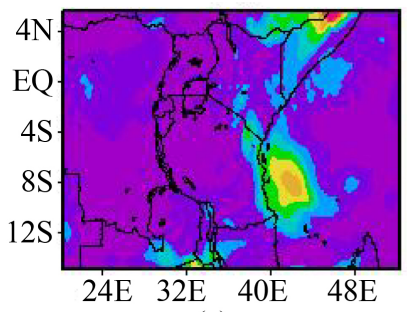

(a)

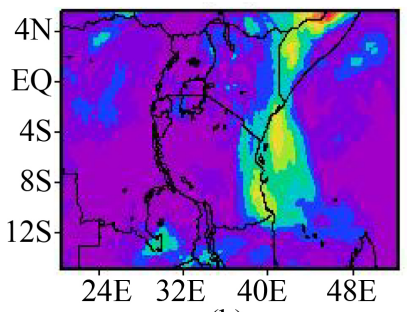

(b)

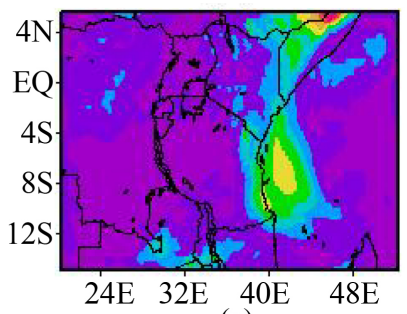

(c)

$$
\begin{array}{llllllll}
2 & 4 & 6 & 8 & 10 & 12 & 14 & 16
\end{array}
$$

Figure 8. The magnitude of the moist potential vorticity vector (in PV-units) on (a) 20/12/2011; (b) 21/12/2011; (c) 20-21/12/2011.

parallel to the coast but also touches most regions along the coast. This collocated with the observed rainfall over the coastal regions. Generally it is seen that the area close to maximum values of the magnitude of $M P V \boldsymbol{V}$ experienced heavy rainfall (Figure 3(a), Figure 4 and Figure 8(a)). To compare the strength of convective systems along the coast regions between day $20^{\text {th }}$ and $21^{\text {st }}$ it can be seen that convection processes was stronger along the coastal regions on $20^{\text {th }}$ than on $21^{\text {st }}$ of December, 2011.

The second case analysed in this study is that occurred on $5^{\text {th }}$ to $7^{\text {th }}$ May, 2015. Figure 9 present distribution of rainfall estimates from the satellite, where subplot 9(a), 9(b) and 9 (c) presents rainfall distribution on $5^{\text {th }}, 6^{\text {th }}$ and $7^{\text {th }}$ May 2015 respectively. It can be seen that most areas received rainfall on the $5^{\text {th }}$ where the coastal region received more rainfall compared to the other regions (Figure $9(\mathrm{a})$ ). On the $6^{\text {th }}$ the amount of rainfall has increased over coastal regions, where the city of Dar es Salaam received heavy rainfall which triggered catastrophic flooding. On the $7^{\text {th }}$ rainfall has increased over the entire coastal regions.

Figures 10-12 represents the distribution of observed rainfall over different regions. These figures present similar patterns as the satellite rainfall estimates. However, the amount of rainfall estimated by satellite is lower than that from the weather stations. The coastal region received more rainfall than other regions and the city of Dar es Salaam received about $111 \mathrm{~mm}$ of rain on $6^{\text {th }}$ May 2015.

The patterns of MPVV follow similar patterns to that of the rainfall, Figure 13 


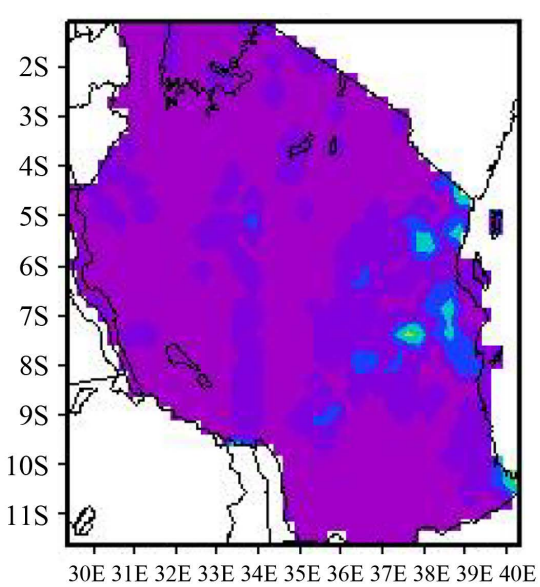

(a)

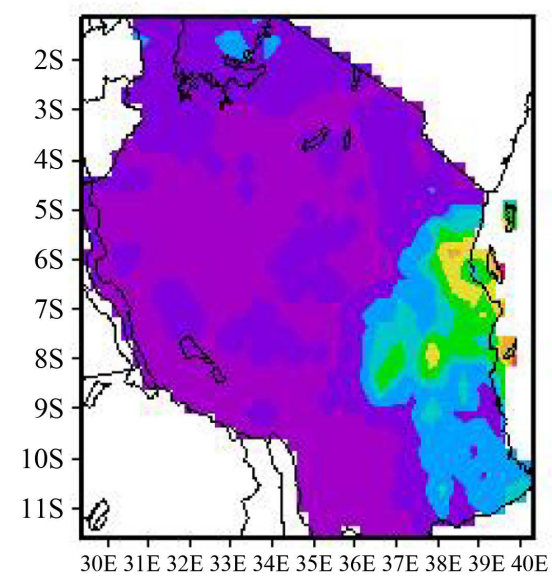

(c)

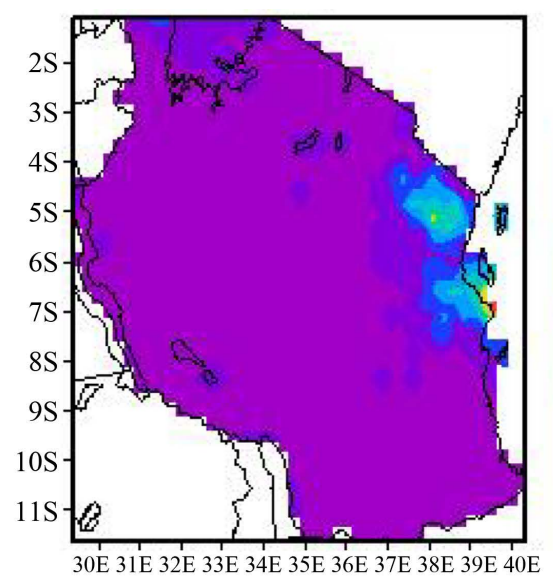

(b)

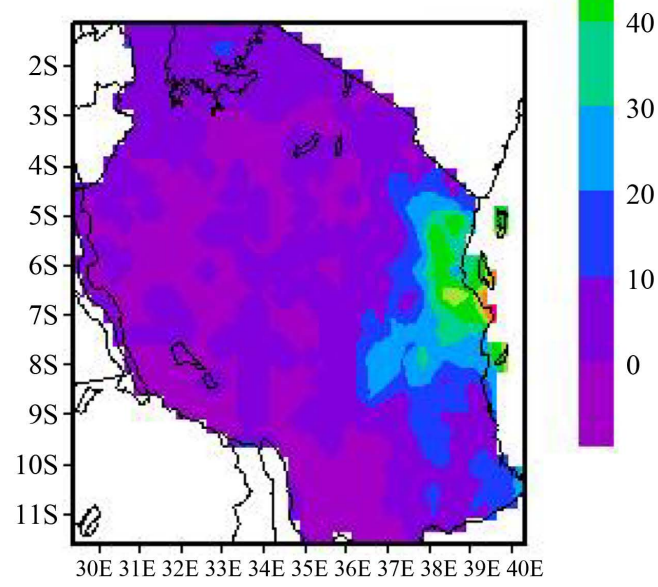

(d)

Figure 9. Rainfall in mm/day (a) 5/5/2015; (b) 6/5/2015; (c) 7/5/2015; (d) 5-7/5/2015.

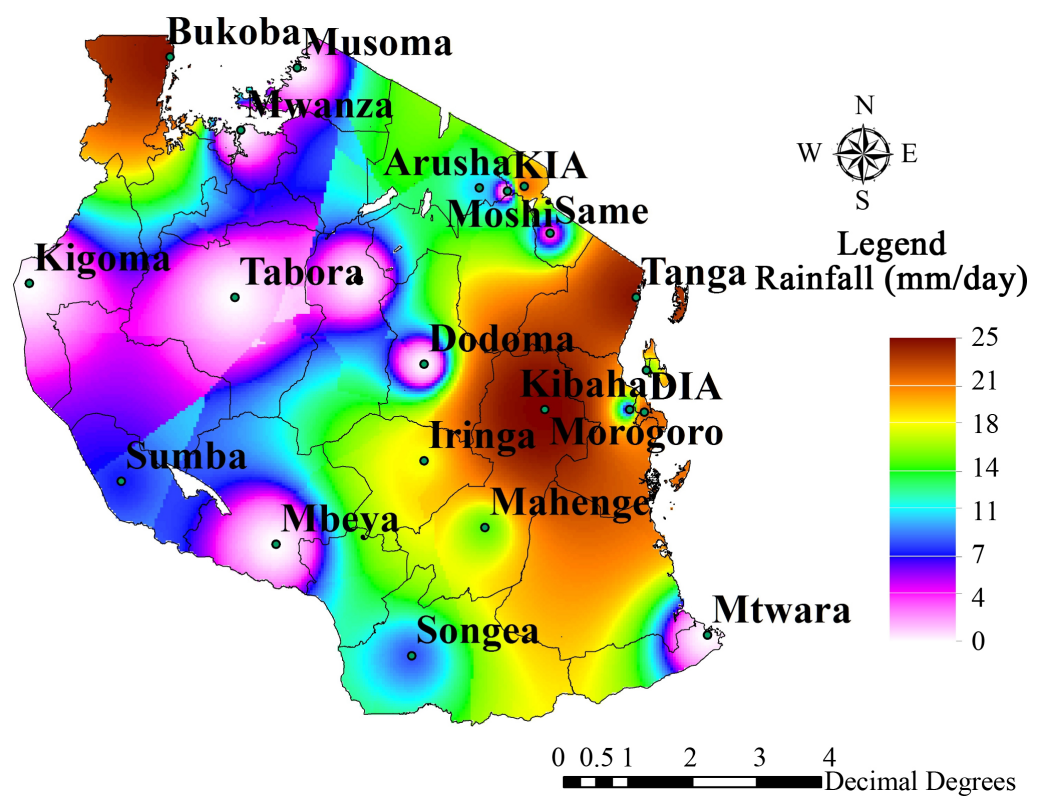

Figure 10. Distribution of observed rainfall over different regions in Tanzania on 5-5-2015. 


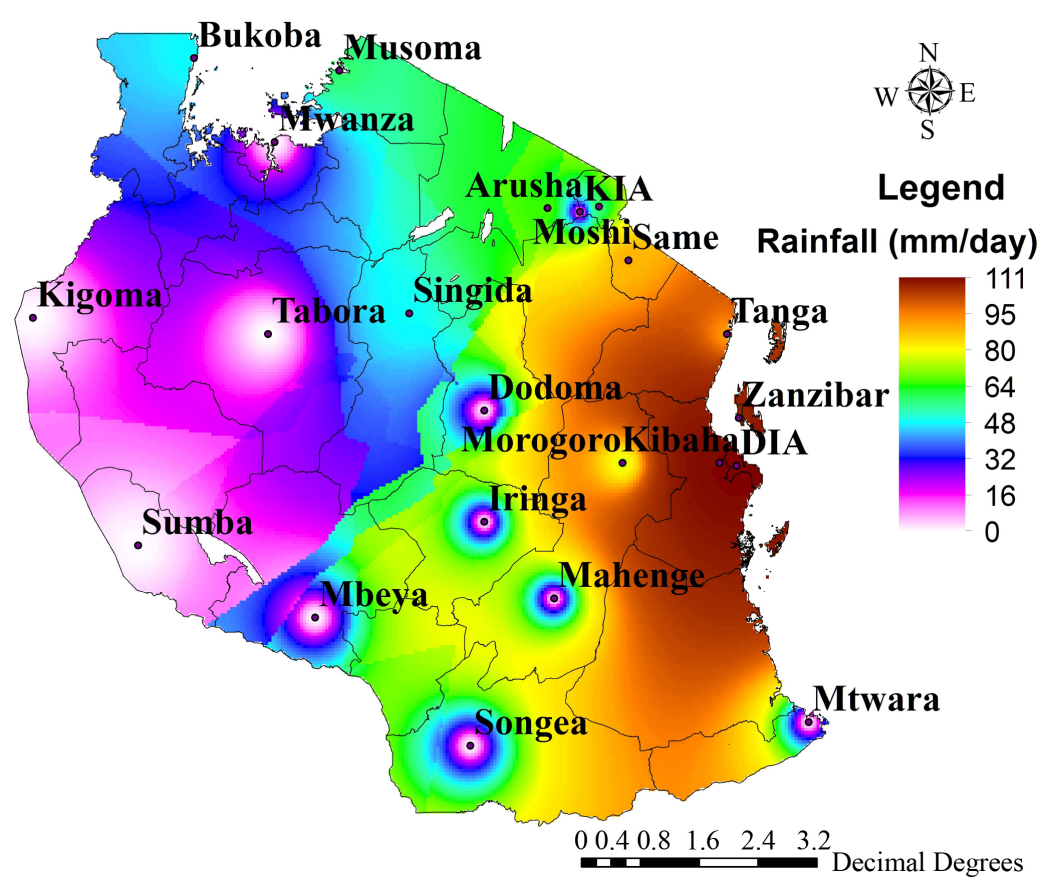

Figure 11. Distribution of observed rainfall over different regions in Tanzania on 6-5-2015.

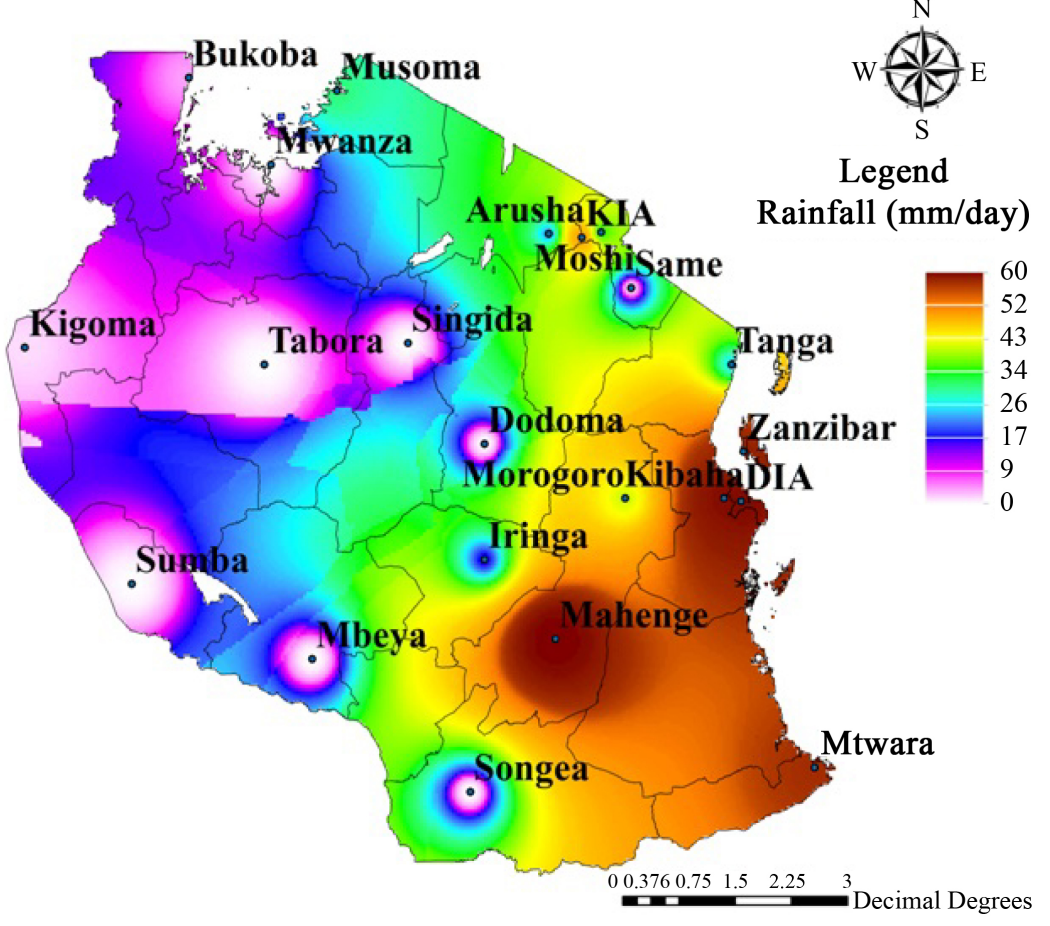

Figure 12. Distribution of observed rainfall over different regions in Tanzania on 7-5-2011.

shows the distribution of the first component of $M P V V$; where on $5^{\text {th }}$ positive values of MPVV dominate almost over the entire domain of Tanzania with maximum val- 
ues located over the northern coast. However, on $6^{\text {th }}$ the positive values of $M P V V$ squeezed to form a kidney shape, extending from northern to parts of southern coastal regions. This band of positive values of $M P V \boldsymbol{V}$ contributed to heavy rainfall over Dar es Salaam. On the $7^{\text {th }}$ the band of positive values of MPVV over the coast relaxed and moved to parts of southwestern high grounds. This might contributed to heavy rainfall events observed over Mahenge (Figure 13).

The distribution of second component of $M P V V$ is shown on Figure 14. Similar pattern to that of the first component is seen. However, the second component shows that on $5^{\text {th }}$ the maximum positive values of $M P V V$ were located close to northern Tanzania Kenya boarder. It moved over northern coast on the $6^{\text {th }}$ and influenced heavy rainfall over those areas. On the $7^{\text {th }}$ the entire coast was dominated with positive values of the second component of MPVV. The third component of MPVV shows little contribution to observed rainfall as it indicates the country was dominated with small positive values of $M P V \boldsymbol{V}$ on the $6^{\text {th }}$ without showing the regions with maximum values especially to the area where received maximum rainfall (Figure 15).

The magnitude of $\boldsymbol{M P V} \boldsymbol{V}$ shows that maximum values of $\boldsymbol{M P V} \boldsymbol{V}$ were located on the northern Tanzania to Kenya boarder on the $5^{\text {th }}$, it then moved to touch the entire northern coast of Tanzania on the $6^{\text {th }}$ (Figure 16). In general the areas with maximum values of the magnitude of $M P V V$ collocate with areas received heavy rainfall.

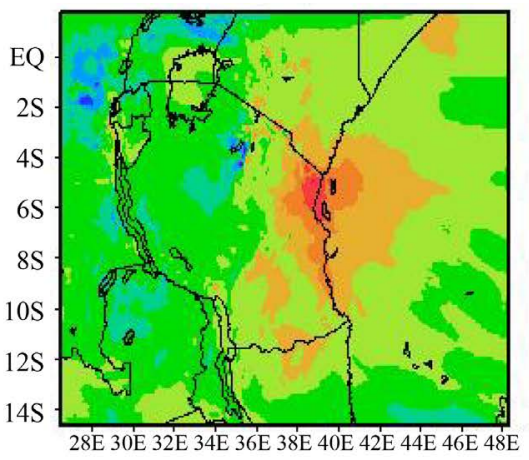

(a)

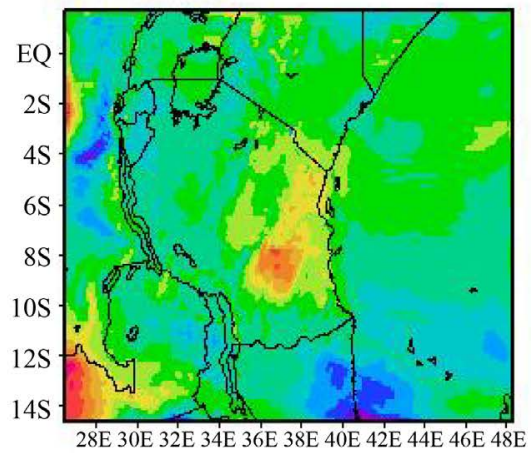

(c)

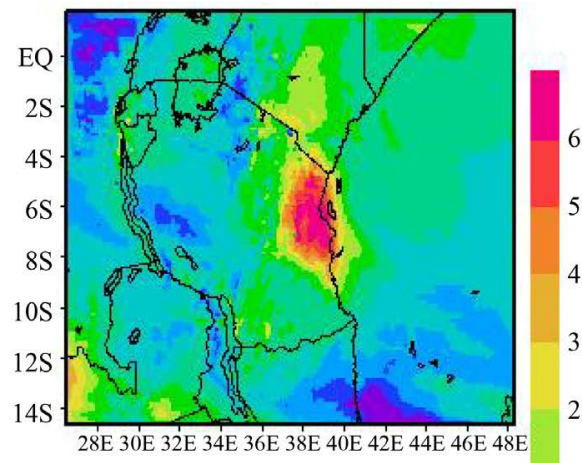

(b)

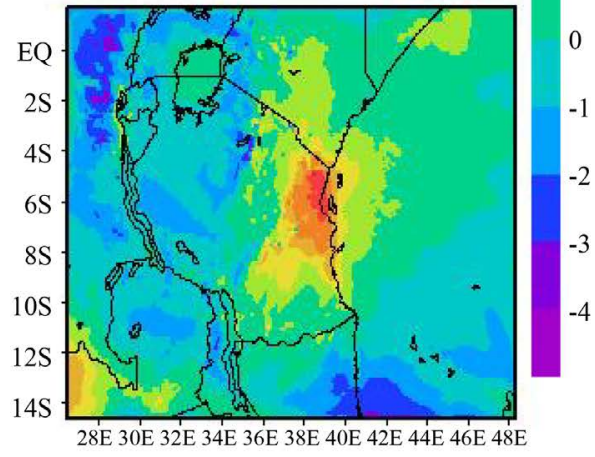

(d)

Figure 13. The first component of the moist potential vorticity vector (in PV-units) (a) at 2015:5:5:00-2015:5:5:22; (b) 2015:5:5:22-2015:5:6:21; (c) 2015:5:6:21-2015:5:7:20; (d) 2015:5:5:002015:5:7:20. 


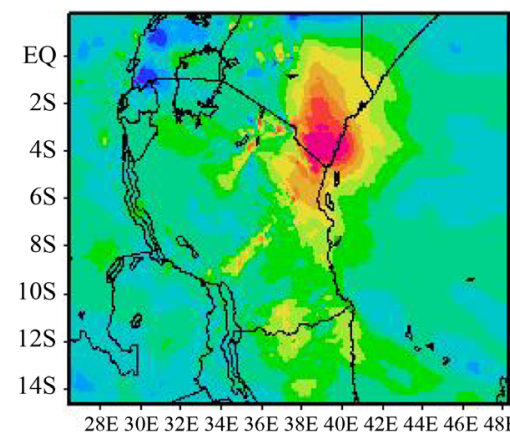

(a)

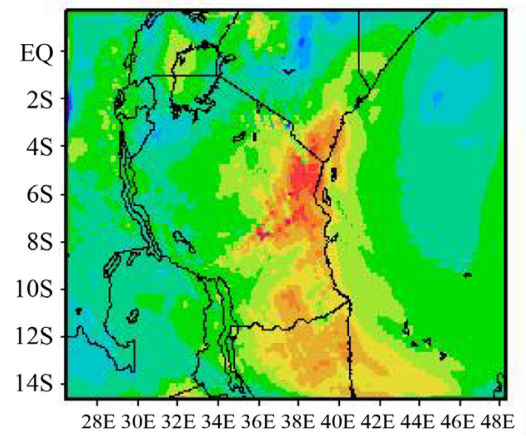

(c)

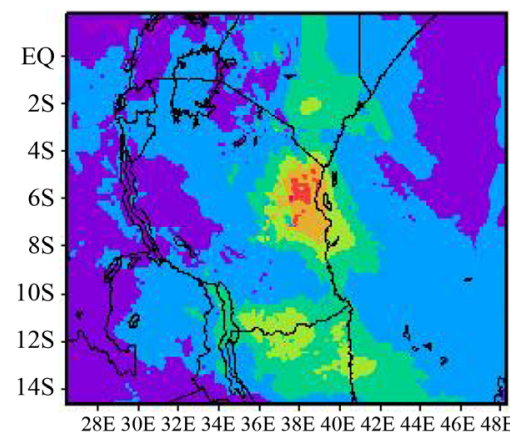

(b)

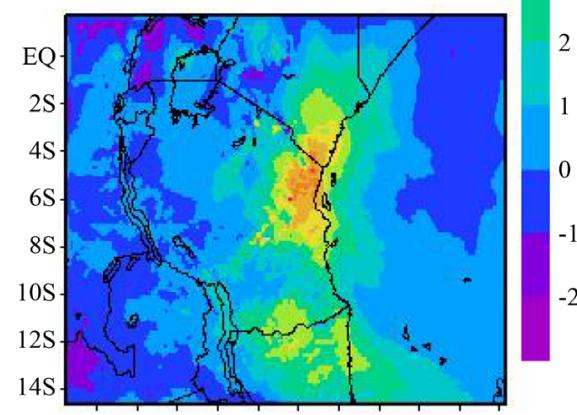

$28 \mathrm{E} 30 \mathrm{E} 32 \mathrm{E} 34 \mathrm{E} 36 \mathrm{E} 38 \mathrm{E} 40 \mathrm{E} 42 \mathrm{E} 44 \mathrm{E} 46 \mathrm{E} 48 \mathrm{E}$

(d)

Figure 14. The second component of the moist potential vorticity vector (in PV-units) (a) at 2015:5:5:00-2015:5:5:22; (b) 2015:5:5:22-2015:5:6:21; (c) 2015:5:6:21-2015:5:7:20; (d) 2015:5:5:002015:5:7:20.

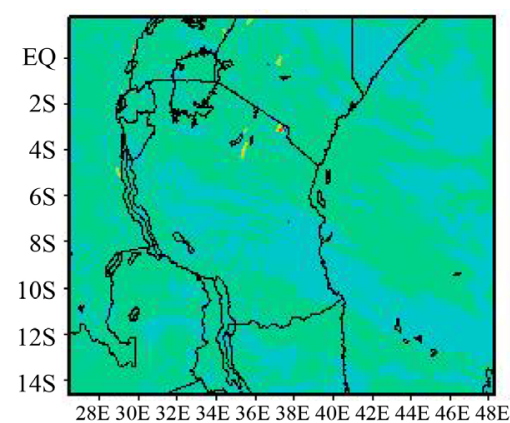

(a)

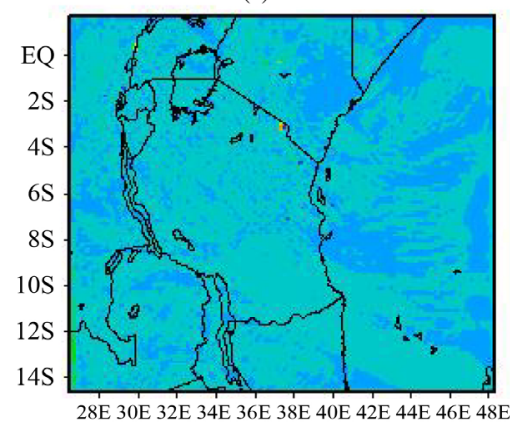

(c)

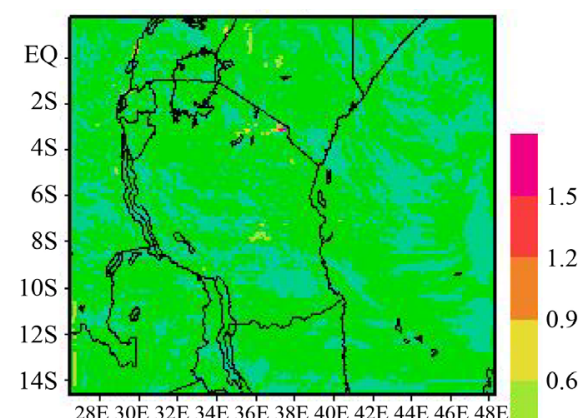

(b)

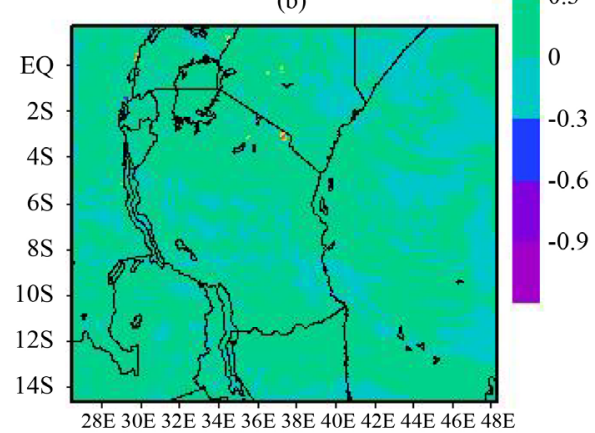

(d)

Figure 15. The third component of the moist potential vorticity vector (in PV-units) (a) at 2015:5:5:00-2015:5:5:22; (b) 2015:5:5:22-2015:5:6:21; (c) 2015:5:6:21-2015:5:7:20; (d) 2015:5:5:002015:5:7:20. 


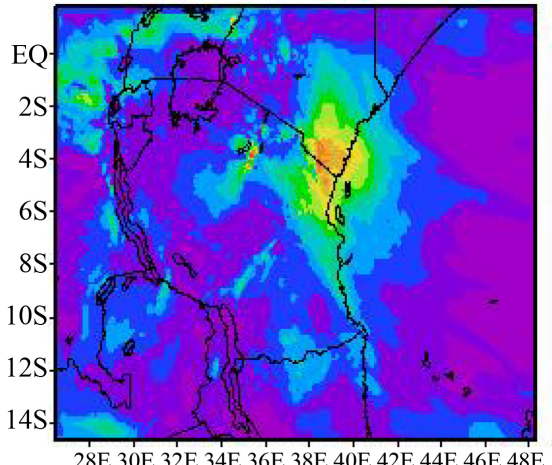

(a)

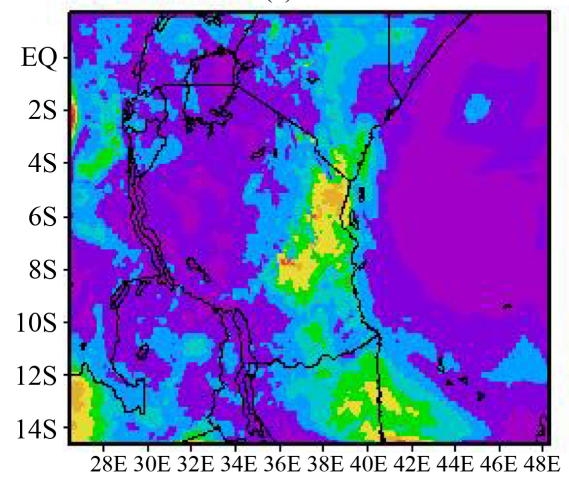

(c)

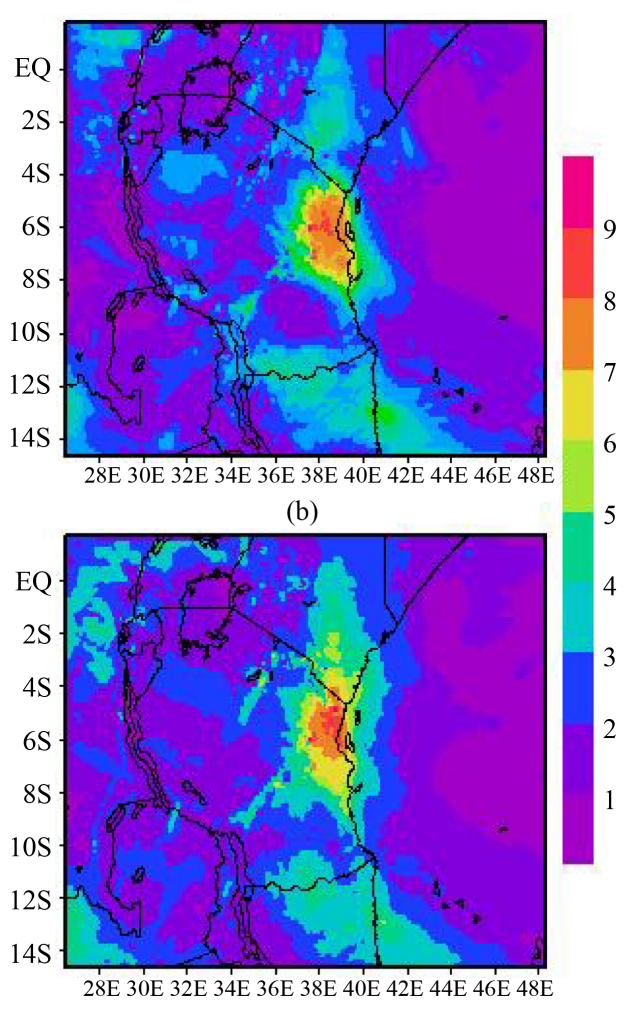

(d)

Figure 16. The magnitude of moist potential vorticity vector (in PV-units) (a) at 2015:5:5:002015:5:5:22; (b) 2015:5:5:22-2015:5:6:21; (c) 2015:5:6:21-2015:5:7:20; (d) 2015:5:5:00-2015:5:7:20.

This gives more confidence that $M P V V$ can be used to diagnose the occurrences of heavy rainfall.

\section{Conclusion and Recommendations}

In this study, we presented a first step of new paradigm, to use the Moist Potential Vorticity Vector MPVV as diagnostic variable of heavy rainfall events in Tanzania. The main purpose of the article was to compute and compare the patterns of MPVV derived from the gradient of the moist-air entropic potential temperature and heavy rainfall events that occurred over different regions in Tanzania on $20^{\text {th }}$ to $22^{\text {nd }}$ December, 2011 and on $5^{\text {th }}$ to $8^{\text {th }}$ May, 2015. Moreover, the article aimed at assessing the relative contributions of horizontal and vertical components of MPVV detecting on the location of the observed heavy rainfall events. Dynamic and Thermodynamic variables: wind speed, temperature, Atmospheric pressure and relative humidity at $600 \mathrm{hPa}$ and 800 $\mathrm{hPa}$ levels generated by the Weather Research and Forecasting (WRF) Model running at Tanzania Meteorological Agency (TMA) were used to compute MPVV at $700 \mathrm{hPa}$ level. It is found that $\mathbf{M P V} \boldsymbol{V}$ can serve as a diagnostic variable of heavy rainfall events over different regions in Tanzania. The first and the second components of $M P V V$ contribute almost equally to locate the areas which received heavy rainfall. Maximum values of MPVV are found to coincide with the areas received heavy rainfall. Although 
we got good relation between $\mathbf{M P V V}$ with heavy rainfall but only five days data were used, therefore we recommended more studies to be done to validate the usefulness of MPVV . Furthermore, it might be interesting if $\boldsymbol{M P V V}$ can be tested to be used as a predictor in climate change studies to help in downscaling climate change projections.

\section{Acknowledgements}

Authors are grateful to the Tanzania Meteorological Agency for provision of observed meteorological data, and the output from WRF model which have been used in this study. Special thanks to Pascal Marquet from the Météo-France, CNRM/GMAP/PROC for the useful discussion on computation of his new novelty moist air entropic potential temperature.

\section{Conflict of Interests}

The authors declare that there is no conflict of interests regarding the publication of this paper.

\section{References}

[1] Hally, A., Richard, E., Fresnay, S. and Lambert, D. (2014) Ensemble Simulations with Perturbed Physical Parametrizations: Pre-HyMeX Case Studies. Quarterly Journal of the Royal Meteorological Society, 140, 1900-1917. http://dx.doi.org/10.1002/qj.2257

[2] Global Weather Hazards Summary (GWHS) (2016) Flooding Risks Elevated as Heavy Rains Forecast to Continue in Southern Tanzania. http://www.fews.net/sites/default/files/Global\%20Weather\%20Hazard-160218.pdf

[3] CNRS (Délégation Paris Michel-Ange) (2013) Elucidating Heavy Precipitation Events. Science Daily. https://www.sciencedaily.com/releases/2013/11/131129101903.htm

[4] Mahmud, M. and Ijaya Kumar, T.S.V.V. (2008) Forecasting Severe Rainfall in the Equatorial Southeast Asia. Geofizika, 25, 109-128. http://geofizika-journal.gfz.hr/vol_25/No2/25_8_mahmud.pdf

[5] Kijazi, A.L. and Reason, C.J.C. (2009) Analysis of the 2006 Floods over Northern Tanzania. International Journal of Climatology, 29, 955-970. http://dx.doi.org/10.1002/joc.1846

[6] Kapala, A., Born, K. and Flohn, H. (1994) Monsoon Anomaly or an El Niño Event in the Equatorial Indian Ocean? Catastrophic Rains 1961/62 in East Africa and Their Teleconections. WMO/TD, 619, 119-126.

[7] Anyah, R.O. and Semazzi, F.H. (2006) Climate Variability over the Greater Horn of Africa Based on NCAR AGCM Ensemble. Theoretical and Applied Climatology, 86, 39-62. http://dx.doi.org/10.1007/s00704-005-0203-7

[8] Liang, Z., Lu, C. and Tollerud, E.I. (2010) Diagnostic Study of Generalized Moist Potential Vorticity in a Non-Uniformly Saturated Atmosphere with Heavy Precipitation. Quarterly Journal of the Royal Meteorological Society, 136, 1275-1288. http://dx.doi.org/10.1002/qj.636

[9] Zhang, D.-L. and Cho, H.-R. (1992) The Development of Negative Moist Potential Vorticity in the Stratiform Region of a Simulated Squall Line. Monthly Weather Review, 120, 13221341. http://dx.doi.org/10.1175/1520-0493(1992)120<1322:TDONMP>2.0.CO;2

[10] Gao, S.T., Wang, X.R. and Zhou, Y.S. (2004) Generation of Generalised Moist Potential Vorticity in a Frictionless and Moist Adiabatic Flow. Geophysical Research Letters, 31, 
L12113. http://dx.doi.org/10.1029/2003GL019152

[11] Yu, Z.F. and Yu, H. (2012) Application of Generalized Convective Vorticity Vector in a Rainfall Process Caused by a Landfalling Tropical Depression, Journal of Tropical Meteorology, 18, 422-435.

[12] Schubert, H.W., Hausman, S.A., Garcia, M., et al. (2001) Potential Vorticity in a Moist Atmosphere. Journal of the Atmospheric Sciences, 58, 3148-3157. http://dx.doi.org/10.1175/1520-0469(2001)058<3148:PVIAMA>2.0.CO;2

[13] Lo, J.C., Yang, Z.L. and Pielke, R.A. (2008) Assessment of Three Dynamical Climate Downscaling Methods Using the Weather Research and Forecasting (WRF) Model. Journal of Geophysical Research, 113. http://dx.doi.org/10.1029/2007JD009216

[14] Ratana, S.B., Ratnam, J.V., Behera, A.K., Rautenbach, C.J., Ndarana, T., Takahashi, K. and Yamagata, T. (2013) Performance Assessment of Three Convective Parameterization Schemes in WRF for Downscaling Summer Rainfall over South Africa. Climate Dynamics, 42, 29312953. http://dx.doi.org/10.1007/s00382-013-1918-2

[15] Hartkamp, A.D., De Beurs, K., Stein, A. and White, J.W. (1999) Interpolation Techniques for Climate Variables. NRG-GIS Series 99-01, CIMMYT, Mexico.

[16] Marquet, P. (2011). Definition of a Moist Entropic Potential Temperature. Application to FIRE-I Data Fights. Quarterly Journal of the Royal Meteorological Society, 137, 768-791. http://arxiv.org/abs/1401.1097 http://dx.doi.org/10.1002/qj.787

[17] Marquet, P. (2014) On the Definition of a Moist-Air Potential Vorticity. Quarterly Journal of the Royal Meteorological Society, 140, 917-929. http://arxiv.org/abs/1401.2006 http://dx.doi.org/10.1002/qj.2182

[18] Marquet, P. (2015). An Improved Approximation for the Moist-Air Entropy Potential Temperature $\theta$ _s. http://arxiv.org/abs/1503.02287

\section{Submit or recommend next manuscript to SCIRP and we will provide best service} for you:

Accepting pre-submission inquiries through Email, Facebook, LinkedIn, Twitter, etc. A wide selection of journals (inclusive of 9 subjects, more than 200 journals)

Providing 24-hour high-quality service

User-friendly online submission system

Fair and swift peer-review system

Efficient typesetting and proofreading procedure

Display of the result of downloads and visits, as well as the number of cited articles

Maximum dissemination of your research work

Submit your manuscript at: http://papersubmission.scirp.org/

Or contact gep@scirp.org 